(Received November 24, 1982)

\title{
FLAME RETARDANT FINISHING OF COTTON FABRICS WITH OLYGOMERIC VINYL PHOSPHONATE AND N-METHYLOLACRYLAMIDE AT LOW TEMPERATURE
}

\author{
By Haruo Sanuki, Kazuhiko Ikeda, Hisashi Someya \\ and Masaichi Onoyama \\ (Department of Material Systems Engineering, Faculty of Engineering, \\ Tokyo University of Agriculture and Technology, \\ Koganei, Tokyo, 184, Japan
}

\begin{abstract}
Cerium (IV) ammonium nitrate (CAN)-initiated copolymerization of oligomeric vinyl phosphonate (OVP), Fyrol 76, with $\mathrm{N}$-methylolacrylamide (NMA) on cotton fabrics at a low temperature $\left(40^{\circ} \mathrm{C}\right)$ was studied, and the results were compared with those obtained by the pad-dry-cure method using persulfate catalyst. An oxygen index (OI) of the cotton fabrics treated by the former method was higher than that for the latter method, in case where these fabrics had the same phosphorus and nitrogen contents. From the relationship between the oxygen index and the phosphorus and nitrogen contents of the fabrics treated by the CAN-initiated copolymerization, it is said that the synergism of nitrogen in enhancing the flame-retarding effectiveness of phosphorus appears remarkably at low phosphorus content. The cotton fabrics treated by the CAN-initiated copolymerization method had a tearing strength higher than those treated by the pad-dry-cure method in case where they had the same oxygen index value.
\end{abstract}

\section{INTRODUCTION}

A flame-retardant oligomeric vinyl phosphonate (OVP), Fyrol 76, was introduced as flame-retardant for cellulosic textile substrates. OVP has been copolymerized with $\mathrm{N}$-methylolacrylamide (NMA) on cotton by persulfate catalyst and heating or by electron beam irradiation ${ }^{2}$ as an initiation source.

In this study we examine the copolymerization of OVP with NMA using cerium (IV) ammonium nitrate (CAN) as initiator at a temperature $\left(40^{\circ} \mathrm{C}\right)$ lower than $150^{\circ} \mathrm{C}$ for the case of persulfate catalyst. The purpose of this study is to demonstrate a possible utility of CAN-initiated copolymerization of OVP with NMA on cotton fabrics to impart improved flame-retardant properties without deteriorating the strength and whiteness of the fabrics. Furthermore the relationship between the flammability of the treated cotton fabrics and their phosphorus and nitrogen contents will be clarified. The effectiveness of this treatment will be compared with that for the case of persulfate. Synergism between nitrogen and phosphorus on the cotton fabrics will be also discussed.

\section{EXPERIMENTALS}

Materials - The fabrics used in this study were 40 's broad cotton ones. The fabrics were further purified by treating in an aqueous solution containing $0.3 \mathrm{wt} \%$ non-ionic surface active agent and $0.05 \mathrm{wt} \% \mathrm{Na}_{2} \mathrm{CO}_{3}$, then throughly washed with water and dried. OVP (Fyrol 76) was supplied by Stauffer Chemical Company. All the other commercial chemical reagents were used without further purifications.

Fabric Sample Treatment - Treatment of the cotton fabrics with OVP, NMA, CAN, and so on in the treating aqueous solution is shown in Table 1. These chemicals were mixed by a mixer, and then the fabric sample was treated in this aqueous solution with stirring at $40^{\circ} \mathrm{C}$ for 1 hour. The bath ratio was $1: 50$. The treated fabrics were washed with a solution containing $0.2 \mathrm{wt} \%$ nonionic surface active agent at $45^{\circ} \mathrm{C}$ for $5 \mathrm{~min}$, completely washed with cold or boiling water, and dried.

Treatment of the cotton fabrics with OVP, NMA, potassium persulfate in the aqueous solution is shown in Table 2. The fabric sample was padded 
in this solution (pick up $90 \%$ ), dried at $80^{\circ} \mathrm{C}$ for $10 \mathrm{~min}$, and then curred at $150^{\circ} \mathrm{C}$ for $5 \mathrm{~min}$. The treated fabrics were washed in a solution containing $0.2 \mathrm{wt} \%$ non-ionic surface active agent at $45^{\circ} \mathrm{C}$ for $5 \mathrm{~min}$, completely rinsed with water, and then dried.

Flammability Measurement -In order to evaluate the flammability of the fabrics, oxygen index $(\mathrm{OI})^{3-5)}$ was determined with a flammability tester ON-1 (Toyo Rika Instruments Inc.) according to JIS K7201 (1976).

Elemental Analyses - Phosphorus analysis was made by the colorimetric analysis of the vanadomolybdate complex following Kjeldahl digestion. 6,7) Nitrogen analysis was performed by Kjeldahl procedure after digestion.

Tearing Strength, Whiteness, and Amount of Free Formaldehyde - The tearing strength was measured according to JIS L1096 and the whiteness

Table 1 Treatment condition in CANinitiated copolymerization method.

\begin{tabular}{l|l}
\hline Water & $29.7-84.7(\mathrm{wt} \%)$ \\
\hline $\begin{array}{l}\text { Wetting } \\
\text { Agent }\end{array}$ & $0.03(\mathrm{wt} \%)$ \\
\hline $\begin{array}{l}\text { Sequestering } \\
\text { Agent }\end{array}$ & $0.1(\mathrm{wt} \%)$ \\
\hline OVP & $10-50(\mathrm{wt} \%)$ \\
\hline NMA & $5-20(\mathrm{wt} \%)$ \\
\hline CAN & $0.136-0.545(\mathrm{wt} \%)$ \\
\hline Temperature & $40\left({ }^{\circ} \mathrm{C}\right)$ \\
\hline Time & $1(\mathrm{hr})$ \\
\hline Bath Ratio & $1: 50$ \\
\hline
\end{tabular}

with a colorimeter $\mathrm{SCH}-2$ (Toyo Rika Instruments Inc.) according to the following equation.

$$
W=0.847 Z
$$

where $W$ is the whiteness and $Z$ one of the tristimulus values. ${ }^{8)}$ An amount of free formaldehyde was estimated by the acetylacetone method according to JIS L1041 (1976).

Laundry Durability - The treated fabrics were washed with aqueous solution containing $0.5 \mathrm{wt} \%$ sodium palmitate at $50^{\circ} \mathrm{C}$ for $30 \mathrm{~min}$. The liquor bath ratio was 1:50. Washed fabrics were rinsed with water and dried at $60^{\circ} \mathrm{C}$. The above process corresponds to one cycle of laundry durability test.

Solubility of Treated Fabrics in Aqueous CupricEthylenediamine Solution - An aqueous cupricethylenediamine solution $(0.5 \mathrm{~mole} / \mathrm{l})$ was prepared according to the reported methods. ${ }^{9-11}$ ) The solubility of the untreated and treated fabrics in this aqueous solution was examined.

\section{RESULTS}

\section{CAN-Initiated Copolymerization Method}

a) Phosphorus Content - A plot of the phosphorus content, $P(\%)$ of the treated fabrics versus NMA concentration of the treating solution at various OVP concentrations and a constant CAN concentration $(0.273 \mathrm{wt} \%)$ is shown in Fig. 1. The phosphorus content was extremely low at any concentration of OVP at $5 \mathrm{wt} \%$ NMA and increased with increasing NMA and OVP concentrations. The phosphorus content is related to the OVP and NMA concentrations by the following

Table 2 Treatment condition in pad-dry-cure method.

\begin{tabular}{c|c|c|c|c|c|c}
\hline No & Watet & $\begin{array}{c}\text { Wetting } \\
\text { Agent }\end{array}$ & $\begin{array}{c}\text { Sequestering } \\
\text { Agent }\end{array}$ & OVP & NMA & $\begin{array}{c}\text { Potassium } \\
\text { Persulfate }\end{array}$ \\
\hline 1 & 78.6 & 0.03 & 0.1 & 10.0 & 11.0 & 0.25 \\
2 & 57.4 & 0.03 & 0.1 & 20.0 & 22.0 & 0.5 \\
3 & 14.9 & 0.03 & 0.1 & 40.0 & 44.0 & 1.0 \\
4 & 89.7 & 0.03 & - & 10.0 & - & 0.25 \\
5 & 79.5 & 0.03 & - & 20.0 & - & 0.5 \\
6 & 59.0 & 0.03 & - & 40.0 & - & 1.0 \\
7 & 88.6 & 0.03 & 0.1 & - & 11.0 & 0.25 \\
8 & 77.4 & 0.03 & 0.1 & - & 22.0 & 0.5 \\
9 & 54.9 & 0.03 & 0.1 & - & 44.0 & 1.0 \\
\hline
\end{tabular}




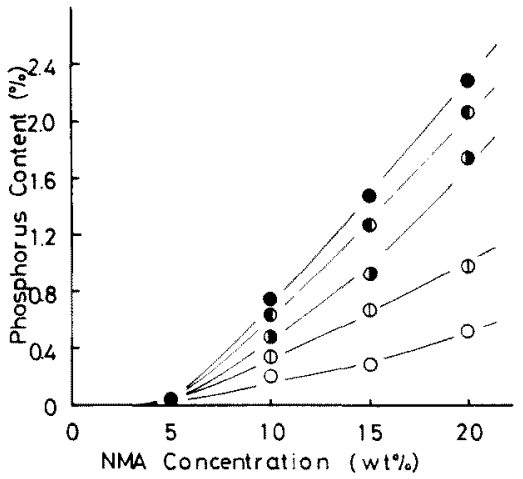

Fig. 1 Relationship between the phosphorus content and NMA concentration at a constant level of CAN $(0.273 \mathrm{wt} \%)$. OVP concentrations are $10 \mathrm{wt} \%(0), 20 \mathrm{wt} \%(0), 30 \mathrm{wt} \%$ (D), $40 \mathrm{wt} \%(\mathbf{O})$, and $50 \mathrm{wt} \%(\mathbf{O})$.

equation.

$$
\begin{gathered}
P(\%)=0.032[\mathrm{OVP}]([\mathrm{NMA}]-5) \\
{[\mathrm{NMA}]>5 \mathrm{wt} \%}
\end{gathered}
$$

The above equation indicates that, even if OVP is contained in the reaction system, the introduction of phosphorus onto the cotton fabrics cannot be attained in the absence of NMA. The CAN concentration dependence of the phosphorus content at various concentrations of NMA and OVP is shown in Fig. 2. In any case, the phosphorus content increased with increasing CAN concentration, though the slope of this plot is reduced with increasing $\mathrm{CAN}$ concentration.

b) Nitrogen Content - Plots of the nitrogen content, $N(\%)$ versus NMA concentration at various OVP concentrations and at a CAN concentration of 0.273 wt $\%$ are shown in Fig. 3. The nitrogen content increased with increasing NMA concentration and slightly with increasing OVP concentration at the NMA concentration above $5 \mathrm{wt} \%$. The nitrogen content is related to OVP and NMA concentrations by the following equation.

$$
\begin{gathered}
N(\%)=0.18[\mathrm{NMA}]+0.014[\mathrm{OVP}]-1.46 \\
{[\mathrm{NMA}]>10 \mathrm{wt} \%}
\end{gathered}
$$

This equation indicates that the introduction of nitrogen onto the cotton fabrics depends mainly on [NMA].

The CAN concentration dependence of the

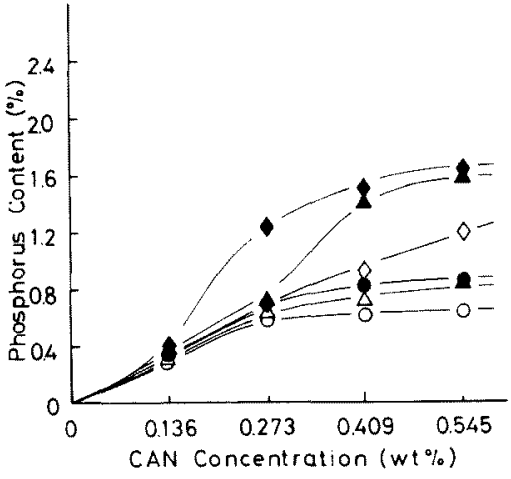

Fig. 2 Relationship between phosphorus content and CAN concentration.

$\begin{array}{lcc} & \text { OVP (wt \%) } & \text { NMA (wt \%) } \\ \diamond & 40 & 10 \\ \triangle & 40 & 15 \\ \Delta & 30 & 10 \\ \bigcirc & 20 & 15 \\ \bullet & 20 & 10\end{array}$

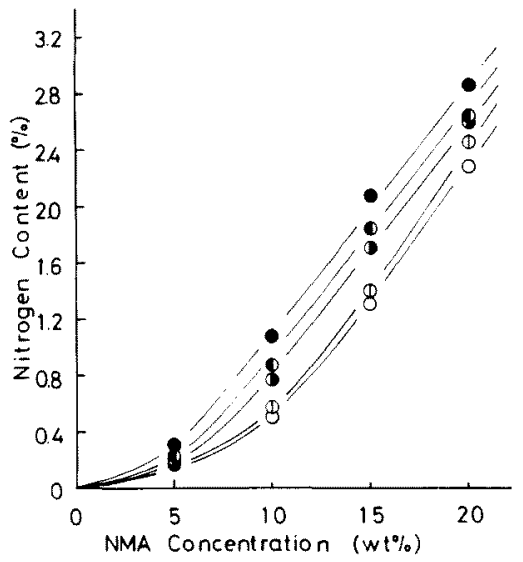

Fig. 3 Relationship between nitrogen content and NMA concentration at a constant level of CAN $(0.273 w t \%)$. Symbols are shown in Fig. 1.

nitrogen content at various concentrations of NMA and OVP is similar to the case for the phosphorus content shown in Fig. 2.

c) Oxygen Index - A plot of the oxygen index (OI) versus the NMA concentration at various OVP concentrations and at a constant concentration of CAN $(0.273 \mathrm{wt} \%)$ is shown in Fig. 4. 


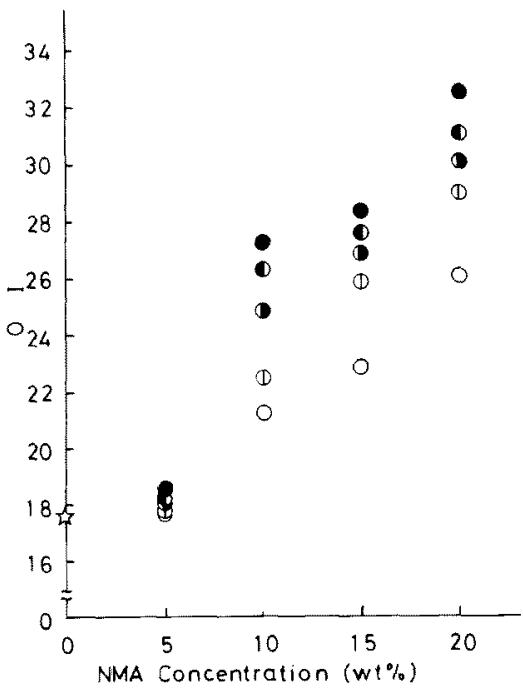

Fig. 4 Relationship between oxygen index and NMA concentration at a constant level of CAN $(0.273 \mathrm{wt} \%)$. Symbols are shown in Fig. 1. in denotes the point for untreated fabrics.

The OI value increased with increasing NMA and OVP concentrations. The CAN concentration dependence of $O I$ at various concentrations of NMA and OVP is similar to the case of the phosphorus content shown in Fig. 2.

d) Tearing Strength — Plots of the tearing strength, $T(\%)$ (the value for the untreated sample was taken as $100 \%$ ) versus NMA concentration at various OVP concentrations and at the constant concentration of CAN is shown in Fig. 5. The tearing strength decreased with increasing NMA concentration, while the decrement of the tearing strength with the NMA concentration was suppressed by OVP. The CAN concentration dependence of the tearing strength at various concentrations of NMA and OVP is shown in Fig. 6, which indicates that $\mathrm{CAN}$ reduces the tearing strength of the cotton fabrics. The tearing strength is related to OVP, NMA and CAN concentrations by the following equation.

$$
T(\%)=100-\frac{1.06[\mathrm{NMA}](1+8.5[\mathrm{CAN}])}{1+0.026[\mathrm{OVP}]}
$$

In the case of high OVP, low NMA and low CAN

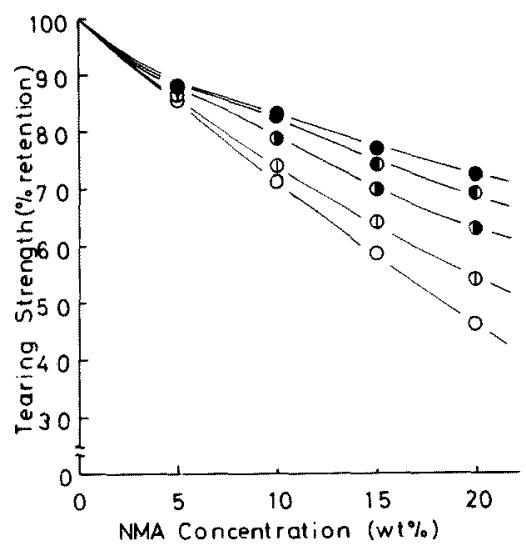

Fig. 5 Relationship between tearing strength and NMA concentration at a constant level of CAN $(0.273 \mathrm{wt} \%)$. Symbols are shown in Fig. 1.

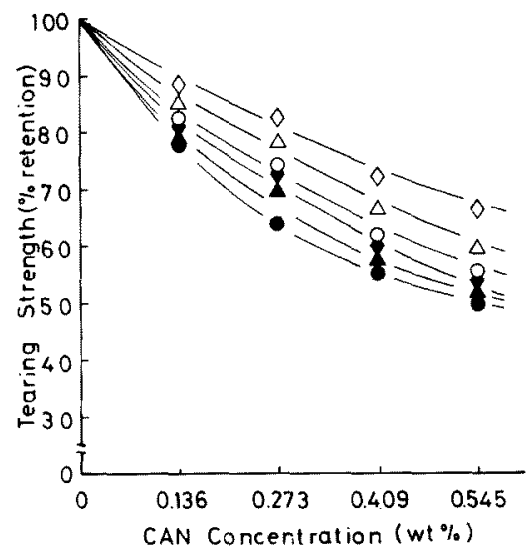

Fig. 6 Relationship between tearing strength and CAN concentration. Symbols are shown in Fig. 2.

concentrations, the mechanical damage of the fabrics is extensively reduced.

e) Whiteness - A plot of the whiteness versus NMA concentration at various OVP concentrations and at a constant concentration of CAN $(0.273$ wt \%) is shown in Fig. 7. The whiteness decreased with increasing NMA concentration, while the relationship between the whiteness and the OVP concentration is not clear. The CAN concentration does not influence the whiteness. The treated fabrics with $W$ value above 60 are not yellow. 


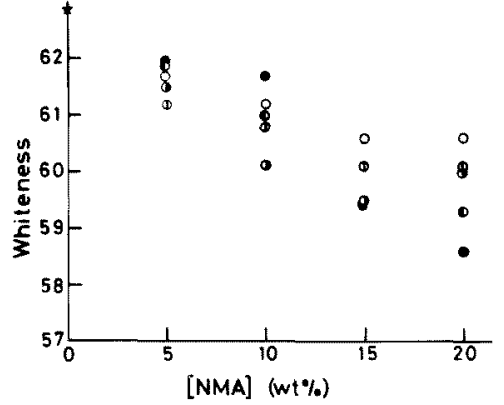

Fig. 7 Relationship between whiteness and NMA concentration at a constant level of CAN $(0.273 w t \%)$. Symbols are shown in Fig. 1.

f) Amount of Free Formaldehyde — Since NMA was used in this flame-retardant treatment, the amount of free-formaldehyde was measured. The values obtained were within the limit, which is legislated for adult $(75 \mu \mathrm{g} / \mathrm{g})$ and infant underwears (difference of absorbance $<0.05$ ) in Japan.

g) Laundry Durability - Plots of the oxygen index versus laundering cycle for various concentrations of NMA, OVP and CAN are shown in Fig. 8. Since the oxygen index slightly decreased with increasing laundry cycles in any case, the treated fabrics are said to be durable to laundry.

h) Solubility of Treated Fabrics in Aqueous Cupric-Ethylenediamine Solution - The treated fabrics were insoluble in aqueous cupric-ethylenediamine solution, while the untreated fabrics were soluble in this solution. The fabrics, to which several monomers were graft-polymerized, are known to be insoluble in this solution..$^{9-11}$ )

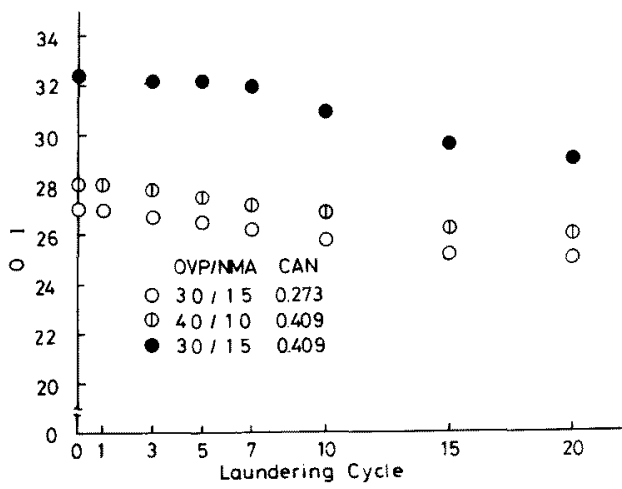

Fig. 8 Dependence of oxygen index on laundry cycle. i) The above data obtained for the treated fabrics washed with boiling water were similar to those for the same fabrics washed with aqueous solution containing $0.2 \mathrm{wt} \%$ non-ionic surface active agent and 0.05 wt $\% \mathrm{Na}_{2} \mathrm{CO}_{3}$.

Persulfate-Initiated Copolymerization Method (PadDry-Cure Method) - Table 3 shows oxygen index, phosphorus content, nitrogen content, tearing strength, and whiteness for the fabrics treated by the persulfate-initiated copolymerization method. The treated fabrics were soluble in aqueous cupricethylenediamine solution though it took a longer time for dissolution than the untreated fabrics. The graft-copolymerization of NMA and OVP to cotton fabrics proceeded slower in the pad-drycure method than in the CAN-initiated copolymerization method.

Table 3 Oxygen index, phosphorus content, nitrogen content, tearing strength, and whiteness for fabrics treated by pad-drycure method.

\begin{tabular}{c|c|c|c|c|c}
\hline No & OI & $P(\%)$ & $N(\%)$ & $T(\%)$ & Whiteness \\
\hline 1 & 21.5 & 0.89 & 0.33 & 73.0 & 64.0 \\
2 & 28.2 & 2.12 & 0.89 & 56.9 & 62.8 \\
3 & 34.2 & 4.21 & 2.42 & 17.5 & 57.6 \\
4 & 20.2 & 0.41 & - & 67.5 & 62.9 \\
5 & 22.0 & 1.58 & - & 57.6 & 61.6 \\
6 & 28.8 & 3.62 & - & 51.5 & 57.3 \\
7 & 18.0 & - & 0.36 & 77.6 & 63.9 \\
8 & 18.0 & - & 0.60 & 71.3 & 63.6 \\
9 & 18.7 & - & 1.66 & 48.7 & 63.4 \\
\hline
\end{tabular}

\section{DISCUSSION}

Relationship between Phosphorus and Nitrogen Content and Oxygen Index - The oxygen index is plotted in Fig. 9 as a function of nitrogen content at a constant CAN concentration $(0.273 \mathrm{wt} \%$ ). Values of Fig. 9 denote the phosphorus contents. The solid lines of Fig. 9 represent the relationship between the oxygen index and the nitrogen content at a constant phosphorus content. The oxygen index is plotted as a function of nitrogen content at several CAN concentrations in Fig. 10. The dependence of oxygen index on the phosphorus and nitrogen contents varied with the CAN concentration of the treating solution. For example, an 


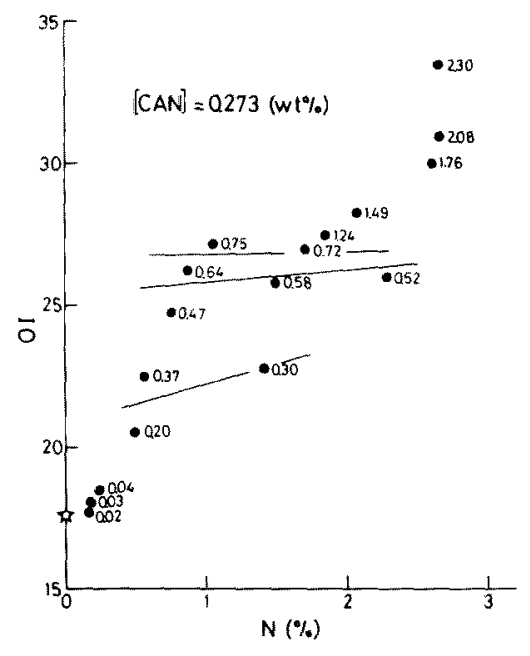

Fig. 9 Relationship between oxygen index and nitrogen content at a constant level of CAN $(0.273 \mathrm{wt} \%)$. Values in figure represent phosphorus content. Solid lines represent the relationship between oxygen index and nitrogen content at a constant phosphorus content.

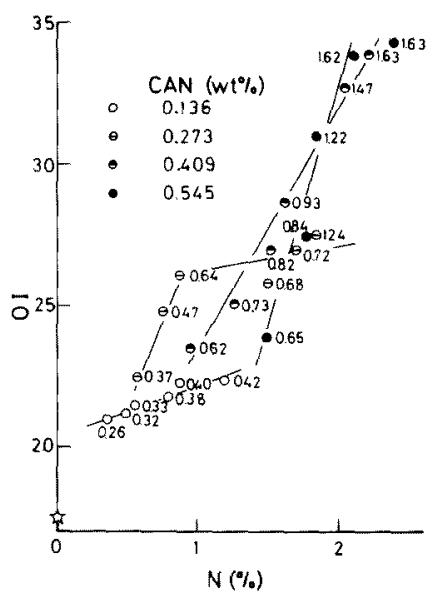

Fig. 10 Relationship between oxygen index and nitrogen content at different levels of CAN. Values in figure show phosphorus content.

oxygen index of ca. 25 was attained at phosphorus, nitrogen and CAN contents of $0.47 \%, 0.7 \%$ and $0.273 \mathrm{wt} \%$, resp. and of $0.73 \%, 1.25 \%$ and 0.409 wt $\%$, resp. This indicates that the oxygen index is not completely defined only by the phosphorus and nitrogen contents. It is known that both the number and the number average molecular weight of branched molecules varies with the concentration of CAN in the case of the graft copolymerization of cellulose with methyl methacrylate. ${ }^{12)}$ These factors may influence the flammability of the present treated cotton fabrics. For the cotton fabrics treated by the pad-dry-cure method, the oxygen index is plotted as a function of nitrogen content in Fig. 11. The solid lines of Fig. 11 are the same as for Fig. 9. In comparison with Fig. 9, phosphorus and nitrogen contribute more effectively to flame-retardancy in the fabrics treated by the CAN-initiated copolymerization method than in the fabrics treated by the pad-dry-cure method. This may be related to the solubility of the treated fabrics in aqueous cupric-ethylenediamine solution. The fabrics treated by the CAN-initiated copolymerization method were insoluble, while those treated by the pad-dry-cure method were soluble. Furthermore, cerium (IV) is known to initiate the graft polymerization of several monomers onto cellulose. ${ }^{12}$ These facts suggest that the methylol group of NMA reacts with the hydroxyl group of cotton fabrics to form ether linkage more extensively than in the case of the pad-dry-cure method. Therefore, phosphorus (or nitrogen) covalently bound to cotton fabrics is more resistant to flame

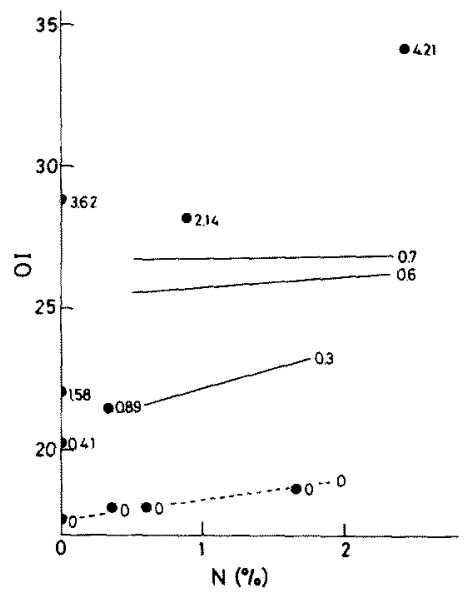

Fig. 11 Relationship between oxygen index and nitrogen content for fabrics treated by paddry-cure method. Values in figure represent phosphorus content. Solid lines represent the relationship between oxygen index and nitrogen content at a constant phosphorus content for the fabrics treated by CAN-initiated copolymerization method shown in Fig. 9. 
than non-covalently bound phosphorus (or nitrogen).

For the Pyrovatex $\mathrm{CP} /$ trimethylolmelaminetreated cotton fabrics, it was shown that the oxygen index was a linear function of the nitrogen content for a given phosphorus concentration and that the slope of the plots increased with increasing phosphorus content from $0.5 \%$ to $1 \%$ and was constant above $1 \% .^{13)}$ This increment of the slope corresponds to synergistic effect of nitrogen. However, this tendency is different from the results obtained in this work. Namely, the data for the phosphorus content of $0 \%$ of Table 3 indicate a very little change of $\mathrm{OI}$ with the nitrogen content. It is, therefore, noted that the slope of the solid line of Fig. 9 increases with increasing phosphorus content from $0 \%$ to $0.3 \%$ and then decreased from $0.3 \%$ to $0.7 \%$. In the OVP/NMA/CAN system, the synergistic effect of nitrogen and phosphorus on the flame retardancy is prominent at a low phosphorus content.

Relationship between Oxygen Index and Tearing Strength - Tearing strength is plotted as a function of oxygen index in Fig. 12. The open and filled circles represent the points for the fabrics treated by the CAN-initiated copolymerization method and by the pad-dry-cure method, resp. On the whole, the tearing strength decreases as the oxygen index increases. For a given oxygen index, fabrics with a high tearing strength are faborable. For an oxygen index of 28 , the tearing strength varied from $50 \%$ to $84 \%$. The treatment composition for the fabrics having a tearing strength of $84 \%$ is $50 \mathrm{wt} \%$ OVP, $10 \mathrm{wt} \%$ NMA, and 0.273 wt $\%$ CAN. On the other hand, it is $20 \mathrm{wt} \%$ OVP, $15 \mathrm{wt} \% \mathrm{NMA}$, and $0.545 \mathrm{wt} \%$ CAN for the fabrics having $50 \%$ as tearing strength. Therefore, an optimum treatment composition for the flameproof cotton fabrics is in a range of high OVP, low NMA, and low CAN concentrations, though it is necessary that the NMA and CAN concentrations are higher than $10 \mathrm{wt} \%$ and $0.273 \mathrm{wt} \%$, respectively. Furthermore, the tearing strength is lower in the fabrics treated by the pad-dry-cure method than in those treated by the CAN-initiated copolymerization method, when they have same OI values. In the former treatment, the curing procedure at $150^{\circ} \mathrm{C}$ for $5 \mathrm{~min}$ may reduce the tearing strength. In this sense, the CAN-initiated

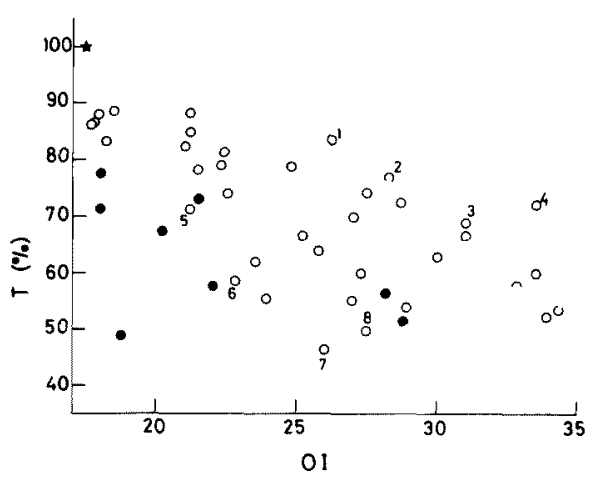

Fig. 12 Relationship between tearing strength and oxygen index. $O$ and show the points for the fabrics treated by the CAN-initiated copolymerization method and by the paddry-cure method, resp.

\begin{tabular}{cccc}
\hline No. & OVP $(w t \%)$ & NMA (wt\%) & CAN (wt\%) \\
\hline 1 & 50 & 10 & 0.273 \\
2 & 50 & 15 & 0.273 \\
3 & 40 & 20 & 0.273 \\
4 & 50 & 20 & 0.273 \\
5 & 10 & 10 & 0.273 \\
6 & 10 & 15 & 0.273 \\
7 & 10 & 20 & 0.273 \\
8 & 20 & 15 & 0.545 \\
\hline
\end{tabular}

copolymerization method is better than the paddry-cure method.

Relationship between Oxygen Index and Whiteness - Whiteness is plotted as a function of oxygen index in Fig. 13. The open and closed circles show the points for the fabrics treated by the CANinitiated copolymerization method and by the pad-dry-cure method, resp. For the former method, the whiteness slightly decreased with increasing oxygen index. In comparison with the tearing strength, there seems no optimum treatment composition in terms of whiteness, because of a very small OI dependency of the whiteness. In other words, the whiteness is not a factor determining the optimum condition for the flameretarding treatment. For the pad-dry-cure method, the whiteness decreased markedly with increasing oxygen index. In the sense of whiteness, the CANinitiated copolymerization method is better than the pad-dry-cure method. 


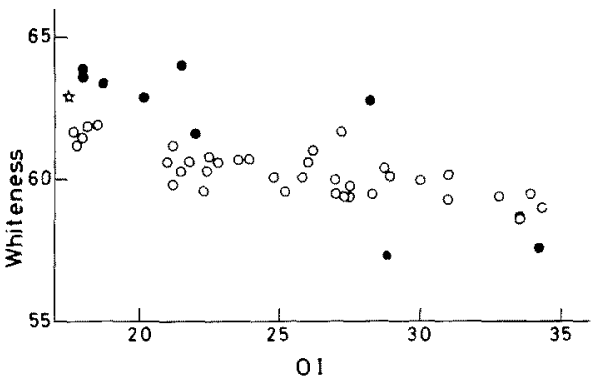

Fig. 13 Relationship between whiteness and oxygen index. 0 and show the points for the fabrics treated by the CAN-initiated copolymerization method and by the pad-dry-cure method, resp.

\section{CONCLUSION}

1. Phosphorus and nitrogen contribute more effectively to flame-retardancy in the fabrics treated by the CAN-initiated copolymerization method than in the fabrics treated by the pad-dry-cure method.

2. In the senses of whiteness and tearing strength, the CAN-initiated copolymerization method is better than the pad-dry-cure method.

3. For the CAN-initiated copolymerization method, the synergism of nitrogen in enhancing the flame-retarding effectiveness of phosphorus remarkably appears at low phosphorus content.

\section{ACKNOWLEDGEMENT}

The authors thank Mr. Kyo Masuda, a director of Meisei Kagaku Kogyo Co., who was so kind as to supply oligomeric vinyl phosphonate oligomer, Fyrol 76.

\section{REFERENCES}

1) B. J. Eisenberg and E. D. Weil; Textile Chem. Colorist, 6, 180 (1974).

2) A. Wieder, C. P. Bittencourt and W. K. Walsh; Textile Chem. Colorist, 9, 109 (1977).

3) C.P. Fenimore and F. T. Martin; Modern Plastics, 45, 141 (1966).

4) M. Furuya; Shohi-Kagaku, 14, 132 (1973).

5) H. Oe; Shohi-Kagaku, 19, 124 (1968).

6) A. Basch and T. Wasserman; Textile Res. J., 40, 246 (1970).

7) D. N. Bernhart and A. R. Wreath; Anal. Chem., 27, 440 (1955).

8) Y. Murata; "Industrial Colorimetry" SeniSha, Osaka (1969) p 40.

9) F. Ide and Y. Takayama; Kogyo Kagaku Zasshi, 64, 213 (1961).

10) H. Sumitomo and Y. Yahama; Kogyo Kagaku Zasshi, 66, 1508 (1963).

11) S. Machida, S. Nishikiori and T. Ueno; Sen-i Gakkaishi, 19, 209 (1963).

12) F. Ide; "Graft Polymerization and Its Application" Kobunshi Kankokai, Kyoto (1977) $\mathrm{p} 45$.

13) J. J. Willard and R. E. Wondra; Textile Res. $J ., 40,203(1970)$.

\section{ビニルホスホネートオリゴマーとN-メチロールアクリルアミド \\ を併用する低温条件下での綿布の難然加工}

$$
\begin{gathered}
\text { 東京農工大学工学部村料システム工学科任貫为夫, 池田和彦, } \\
\text { 染谷 恒, 尾野山政一 }
\end{gathered}
$$

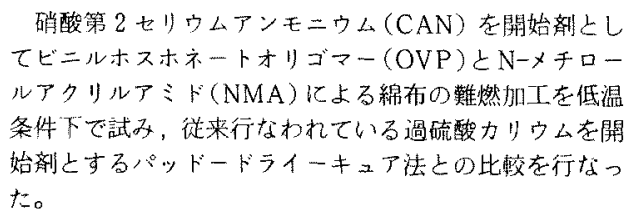

硝酸第 2 七りウムアンモニウム(CAN) を開始剂とし

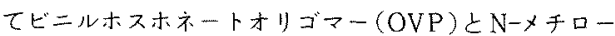
ルアクリルアミド(NMA)による綿布の難燃加工を低温 条件下で試み，従来行な加ている過硫酸力りウムを開 始剤とするパッドードライーキュア法との比較を行な。 た。

難燃效果は酸集指数法によって半定した。同一の含り
ン率，含室素率を持つ有を比較すると，CAN を開始剂 しして用い $40^{\circ} \mathrm{C}$ で加工した本法の方が高い難燃性を示し た。また引裂強度の面でも同し有効な蜼然効果を示す布 を比较すると本法の万加良好であった。また難燃效果に 対するリンと空菜の相乗効果についてはリン含量の小さ な領域で影著に現れた。 